\begin{tabular}{|c|c|c|c|}
\hline Article Info & RESEARC ARTICLE & ARAŞTIRMA MAKALESİ & \\
\hline Title of Article & \multicolumn{2}{|c|}{$\begin{array}{l}\text { Interdisciplinary Information Systems in Disaster } \\
\text { Management }\end{array}$} & \\
\hline $\begin{array}{l}\text { Corresponding } \\
\text { Author }\end{array}$ & \multicolumn{2}{|c|}{$\begin{array}{l}\text { Fazel Ahmad Siawash OCHMAS } \\
\text { İstanbul Aydın Üniversitesi, Fen Bilimler Enstitüsü, Mimarlık Ana Bilim Dalı, } \\
\text { fazelahmadochmas@yahoo.com }\end{array}$} & a \\
\hline $\begin{array}{l}\text { Submission Date } \\
\text { Admission Date }\end{array}$ & \multicolumn{2}{|l|}{ 07.09.2019 / 07.12/2019 } & KENT \\
\hline Author / Authors & $\begin{array}{l}\text { Fazel Ahmad Siawash OCHMAS } \\
\text { Süleyman BALYEMEZ }\end{array}$ & $\begin{array}{l}\text { ORCI D: } 0000-0002-7910-4616 \\
\text { ORCI D: } 0000-0001-5428-8829\end{array}$ & AKADEMİSİ \\
\hline How to Cite & \multicolumn{2}{|c|}{$\begin{array}{l}\text { OCHMAS, F.A.S., BALYEMEZ, S. (2019). Interdisciplinary Information Systems in } \\
\text { Disaster Management, Kent Akademisi, Volume, } 12 \text { (40), Issue 4, Pages 779-791. }\end{array}$} & How to Cite \\
\hline
\end{tabular}

\title{
Afet Yönetiminde Disiplinler Arası Bilgi Sistemleri
}

\section{ABSTRACT:}

Fazel Ahmad Siawash OCHMAS ${ }^{1}$ Süleyman BALYEMEZ ${ }^{2}$

Accurate estimation of disaster risks is possible with determination of current vulnerability. By combining these researches in different disciplines and gathering them on appropriate platforms and sharing them, the correct information to be created will enable the risk reduction planning to reach its purpose and enable the complete disaster management system to be constructed flawlessly. The HAZUS system, which has been actively used in the United States for a long time, is one of the most advanced disaster management and data sharing tools available today. In this study, the working methodology of HAZUS has been examined and clues for the development of the AYDES system, which has been constructed according to the conditions of our country in the recent past, have been tried to be revealed.

Keywords: Disaster management, Hazard and risk, Urban vulnerability, Data sharing systems.

ÖZ:

Afet risklerinin doğru tahmin edilebilmesi mevcut hassasiyetlerin tespiti ile mümkündür. Farklı disiplinlerin çalışma alanlarına giren bu araştırmaların uygun platformlarda bir araya getirilmesi ve paylaşıma açılması ile oluşturulacak sağlıklı bilgi, risk azaltma planlamasının amacına ulaşabilmesini sağlarken, bütüncül afet yönetim sisteminin de kusursuz kurgulanabilmesine olanak tanıyacaktır. Bu alanda oldukça geniş bir birikime sahip Amerika Birleşik Devletlerinde uzun süredir aktif olarak kullanılan HAZUS sistemi günümüzün en gelişmiş afet yönetimi ve bilgi paylaşımı araçlarından biridir. Bu çalışmada HAZUS çalışma sistemi incelenmiş ve yakın geçmişte ülkemiz koşullarına göre kurgulanarak hayata geçirilen AYDES sisteminin geliştirilmesine yönelik ipuçları ortaya çıkarılmaya çalışılmıştır.

Anahtar Kelimeler: Afet yönetimi, Tehlike ve risk, Kentsel hassasiyet, Bilgi sistemleri.

\footnotetext{
${ }^{1}$ İstanbul Aydın Üniversitesi, Fen Bilimler Enstitüsü, Mimarlık Ana Bilim Dalı, fazelahmadochmas@yahoo.com

${ }^{2}$ İstanbul Aydın Üniversitesi, Mimarlık ve Tasarım Fakültesi, Mimarlık Bölümü, Dr. Öğr. Üyesi, suleymanbalyemez@aydin.edu.tr
} 


\section{GíRiş:}

Özellikle gelişmekte olan ülkelerde, kentlerin hızlı ve büyük oranda kontrolsüz büyümesi neticesinde, afetler karşısında hassas ve kırılgan kentsel dokular oluştuğu ve kayıpların bu tür alanlarda yoğunlaştı̆̆ görülmektedir. Günümüzde insan hayatı, deprem, sel, kasırga, toprak kayması, tsunami gibi çeşitli doğal afetlerin tehdidi altındadır. $\mathrm{Bu}$ afetler arasında dünya genelinde en çok can ve mal kaybına neden olan doğal afet depremdir. Depremler oluş nedenlerine göre volkanik, tektonik, çöküntü ve insan kaynaklı depremler olarak gruplanmakta olup (Rezayiyan, 2002) meydana gelen tüm depremlerin \%90'ı tektonik depremlerdir (İbrahimi ve Cezayirli, 1995). Yirminci yüzyılda dünyanın farklı noktalarında meydana gelen 1100'den fazla yıkıcı depremde 1,5 milyon insan hayatını kaybederken, ölümlerin \% 90’ı binaların depreme karşı yeterli güvenliğinin olmamasından kaynaklanmıştır (Alahi, 2018).

Bugünkü bilimsel ve teknolojik olanaklarla zamanı tam olarak önceden kestirilemeyen depremler, bu anlamda küresel ölçekte en başta gelen afet tehlike unsurudur. Bu durum kentlerin depremlere karşı hassasiyetinin azaltılması gerekliliğini ortaya koymaktadır. Zira gerek depremler gerekse diğer afetler nedeniyle oluşan can ve mal kaybının yanı sıra, ikincil ve dolaylı etkiler neticesinde ortaya çıkan ekonomik yükler, ülkelerin ekonomik büyüklüklerine oranla oldukça yüksek olabilmektedir. Kentlerin afet hassasiyetinin azaltılması, kent planlama, mimarlık, inşaat mühendisliği ve yer bilimleri disiplinlerinin ortak çalışmasıyla üstesinden gelinebilecek bir hedef olarak görülmektedir. Bu bağlamda ilk adım, kentin bileşenlerinin hassasiyetini tespit etmek, hassas kentsel alanları ve dokuları tanımlamak ve bu alanların mikro bölgelemesi ile mevcut modelleri kullanarak analiz etmek ve değerlendirmek, kent planlama perspektifinden afet etkilerini azaltmak için bilimsel ve pratik çözümler sunmaktır (Gispen, 2002).

Kent, doğal, yapılaşmış ve sosyal çevrelerden ibaret bir bütündür. Afet risklerinin doğru tahmin edilebilmesi tüm bu çevrelerde mevcut hassasiyetlerin tespiti ile mümkündür. Farklı disiplinlerin çalışma alanlarına giren bu araştırmaların uygun platformlarda bir araya getirilmesi ile sağlıklı bilgi oluşturulabilecektir. Bu noktada esas mesele farklı disiplinlerce üretilen verinin, diğer disiplinler ve kamu idaresi tarafından da anlamlandırılabilecek, afet risklerini azaltma hedefine yönelik bilgi demetlerine dönüştürülebilmesidir.

Özellikle gelişmiş ülkelerde afet yönetimi, risk belirleme ve azaltma ile afet sonrası müdahale konularında geliştirilen veri tabanları ve yazılımlar giderek daha etkin araçlar olarak kullanılmaktadır. Amerika Birleşik Devletleri'nde FEMA (Federal Emergency Management Agency - Federal Acil Durum Yönetim Dairesi) kontrolünde geliştirilen ve kullanılmakta olan HAZUS (Hazard United States) bu alanda en geniş veri tabanına ve en yaygın kullanıma sahip sistem olarak öne çıkmaktadır. Kanada'da NHEMATIS (Natural Hazards Electronic Map and Assessment Tools Information System), Rusya'da EXTREMUM, Tayvan'da TELES (Taiwan Earthquake Loss Estimation System) gibi sistemler yine bu çerçevede öne çıkan sistemler arasındadır. Avrupa Birliği ise Avrupa'da afet yönetimi ve deprem risk değerlendirmesi için büyük bir proje olan LESSLOSS sistemini finanse etmektedir. Türkiye'de HAZUS sistemini esas alan ve Türkiye için uyarlanarak geliştirilmesine başlanan HAZTURK (Hazard Turkey) sistemi tamamlanmamış olup aktif olarak kullanılmamaktadır. Bunun yerine yakın geçmişte AFAD tarafından AYDES (Afet Yönetimi ve Karar Destek Sistemi) kullanıma sunulmuş durumdadır.

Bahsi geçen sistemler değişen yetkilendirme dereceleri ile kısıtlı bir kullanıcı kitlesinin erişimine açık, genel olarak yerel kullanım özelliğine sahip sistemlerdir. Filemon ve Uriarte (2008), bu sistemler arasında HAZUS'un daha geniş bir yetkilendirilmiş kullanıcı profiline sahip olduğunu ve küresel olarak farklı ülkelere uyarlanabilir nitelikte olduğunu belirtmektedir.

Bu doğrultuda çalışmada, afet yönetiminin farklı safhalarında somut bilgi sunan dünya genelindeki sistemler arasında farklı türevleri ile en yaygın ve en geniş kullanım alanına sahip HAZUS sistemi incelenmiş ve Türkiye özelinde kullanıma sunulan AYDES üzerinde durulmuştur. Sistemlerin anlaşılır olabilmesi için öncelikle afet ve afet yönetimi kavramları ele alınmış, dünya genelinde en çok can ve mal kaybına sebep olan afet türü olması nedeniyle kavramların ele alınışında yer yer depremle ilişkilendirilme yoluna başvurulmuştur.

\section{AFET VE AFET YÖNETIMI}

Afet, yol açtığı fiziksel, sosyal, ekonomik ve çevresel kayıplar nedeniyle, toplumsal yaşamın sekteye uğraması sonucunu doğuran ve toplumun kendi olanak ve kaynakları ile üstesinden gelemeyeceği, doğal, teknolojik veya insan kökenli olayların sonuçları; diğer bir ifadeyle, olayın kendisi değil sonucu şeklinde tanımlanmaktadır. Afetin 
büyüklüğü ise ortaya çıkan can ve mal kayıpları, yaralanmalar, hasara uğrayan yapılar ve bu bağlamda oluşan çevresel, sosyal ve ekonomik kayıpların miktarı ile ölçülmektedir (Gispen, 2002). Afetin büyüklüğünü belirleyen ana etkenleri, olayın fiziksel büyüklüğü, olayın yoğun yerleşme alanlarına olan uzaklığı, yoksulluk, az gelişmişlik, hızlı nüfus artışı, tehlike potansiyeline sahip alanlarda hızlı ve denetimsiz şehirleşme ve sanayileşme, doğal çevrenin tahrip edilmesi, bilgisizlik ve eğitimsizlik, toplumun afet olaylarına karşı önceden alabileceği koruyucu, önleyici ve risk azaltıcı önlemlerin ulaştığı düzey olarak sıralamak mümkündür (Khorram ve Manesh, 2017).

Afetler meydana geliş hızlarına göre ani gelişen ve yavaş gelişen afetler olarak ikiye ayrılırken kökenlerine göre de jeofizik, meteorolojik, teknolojik ve insan kökenli olarak sınıflandırılmaktadır. Afetlerin insan toplulukları ve ekonomi üzerindeki etkileri ise doğrudan, dolaylı ve ikincil etkiler olarak gruplanmaktadır.

Can kayıpları, yaralanmalar, maddi kayıplar, hayvan ve tarım ürünleri kayıpları, kültür mirası ve müzelerdeki kayıplar, kurtarma, ilk yardım ve geçici barınma çalışmaları giderleri, tedavi giderleri, alt yapı hasarları ile strüktürel hasarlar ve bunların onarım giderleri deprem afetinin doğrudan etkileri arasındadır (Demirci ve Karakuyu, 2004).

Dolaylı etkiler ise işyerleri ve sanayi kuruluşlarının hizmet veremez ve üretim yapamaz hale gelmeleri nedeniyle yaşanan üretimdeki dramatik azalmayı, sağlık ve eğitim başta olmak üzere kamu hizmetlerinin durması veya aksaması sebebiyle oluşan hizmet kayıplarını, kente servis veren temel hizmet sektörlerinde öngörülemeyen bir zaman dilimine yayılan işletme kayıpları sebebiyle yaşanan gelir kayıplarını, bunlar sonucunda ortaya çıkan üretim ve hizmet yetersizliği nedeniyle fiyat artışları yaşanmasını, kamu ve özel sektöre ait kaynakların çok büyük bir oranda aramakurtarma, ilk yardım ve geçici barınma çalışmalarına aktarılması sebebiyle diğer alanlara yapılacak yatırım ve hizmetlerin azalmasını ve bunlarla ilişkili diğer maliyetleri, ülke kalkınma programının aksamasına bağlı olarak oluşacak ilave maliyetleri, işsizlik, göç, yaralı insanlar ve kimsesiz kalanlarla ilişkili olarak ortaya çıkan diğer toplumsal maliyetleri kapsar (Demirci ve Karakuyu, 2004).

Üretim kaybı ve bunun doğal sonucu olarak oluşan arz kaybı, arz kaybının sebep olduğu pazar kaybı, ulusal kaynakların afet bölgesine aktarılmasının yol açabileceği ve ayrıca arzın talebi karşılamaması sonucu oluşabilecek fiyat artışları, bütçe giderlerinin öngörülenin üzerinde artması, mali kaynakların tükenmesi ve ödemeler dengesinin bozulması, yatırım için ayrılan kaynakların afet bölgesine yönlendirilmesi sebebiyle yatırımların durması, gelir kalemi olarak vergi artışları ve dış borçlanma gereksiniminin kaçınılmaz olması ise ikincil etkilerdir (Demirci ve Karakuyu, 2004).

Kökenleri ve gelişim hızları ne olursa olsun, tüm afet olayları ile ilgili yönetim süreci, aşağıda sıralanan ve şekil 1'de gösterilen aşamalardan oluşur (Özmen vd, 2005). Afet öncesine ilişkin ilk iki safha risk yönetimi, afet sonrasına ilişkin safhalar ise kriz veya acil durum yönetimi olarak adlandırılır.

1. Risk azaltma aşaması: Afet tehlikesinin ve risklerinin indirgenmesi veya muazzam kayıplarla sonuçlanmaması hedefiyle alınacak önlemler ve eylemler risk azaltma safhasında yapılmalıdır. Bu aşama esasen, iyileştirme veya yeniden inşa aşamasındaki eylemlerle birlikte başlar ve yeni bir afet olana kadar devam eder.

2. Hazırlık aşaması: Tehlikenin toplum açısından olumsuz etkiler doğurabilecek sonuçlarına karşı önlemler alarak, zamanında, en uygun şekilde ve en etkili organizasyon ve metotlarla ortadan kaldırmak hazırlık aşamasında yapılması gereken çalışmaların ana hedefleridir.

3. Müdahale aşaması: Bir afetin meydana gelmesinden hemen sonra başlar ve afetin büyüklüğüne bağlı olarak en çok 1-2 aylık bir zaman dilimini kapsar. Bu zaman zarfında yapılan eylemlerin ana hedefi olabildiğince kısa süre içinde en fazla insanın hayatını kurtarmak, yaralıların tedavilerini gerçekleştirmek ve evsiz kalanların beslenme, giyinme, ısınma, barınma, korunma vb. gibi yaşamsal ihtiyaçlarını en uygun yöntemlerle karşılamaktır.

4. İyileştirme aşaması: Bu aşamada yürütülen eylemlerin temel hedefi, afete maruz kalan toplulukların haberleşme, ulaşım, su, elektrik, kanalizasyon gibi teknik altyapı olanakları ile eğitim, psiko-sosyal destek, uzun süreli geçici barınma, ekonomik ve sosyal ihtiyaçlar vb. gibi yaşamsal ihtiyaçlarının minimum düzeyde karşılanması için gerekli tüm çalışmaları gerçekleştirmektir.

5. Yeniden inşa aşaması: Afete maruz kalan ve zarar gören tüm insan aktivitelerinin afet öncesi seviyeden daha ileri bir seviyede karşılanması bu aşamada gerçekleştirilecek eylemlerin temel hedefidir. Bu eylemler arasında yıkılan ve hasar gören tüm yapı ve tesislerin yeniden inşa edilmesinin yanı sıra, toplumun afet 
sebebiyle bozulan ekonomik, sosyal ve psikolojik bütünlüğünün de onarılması gibi çok geniş bir alana yayılan eylemler yer almaktadır.

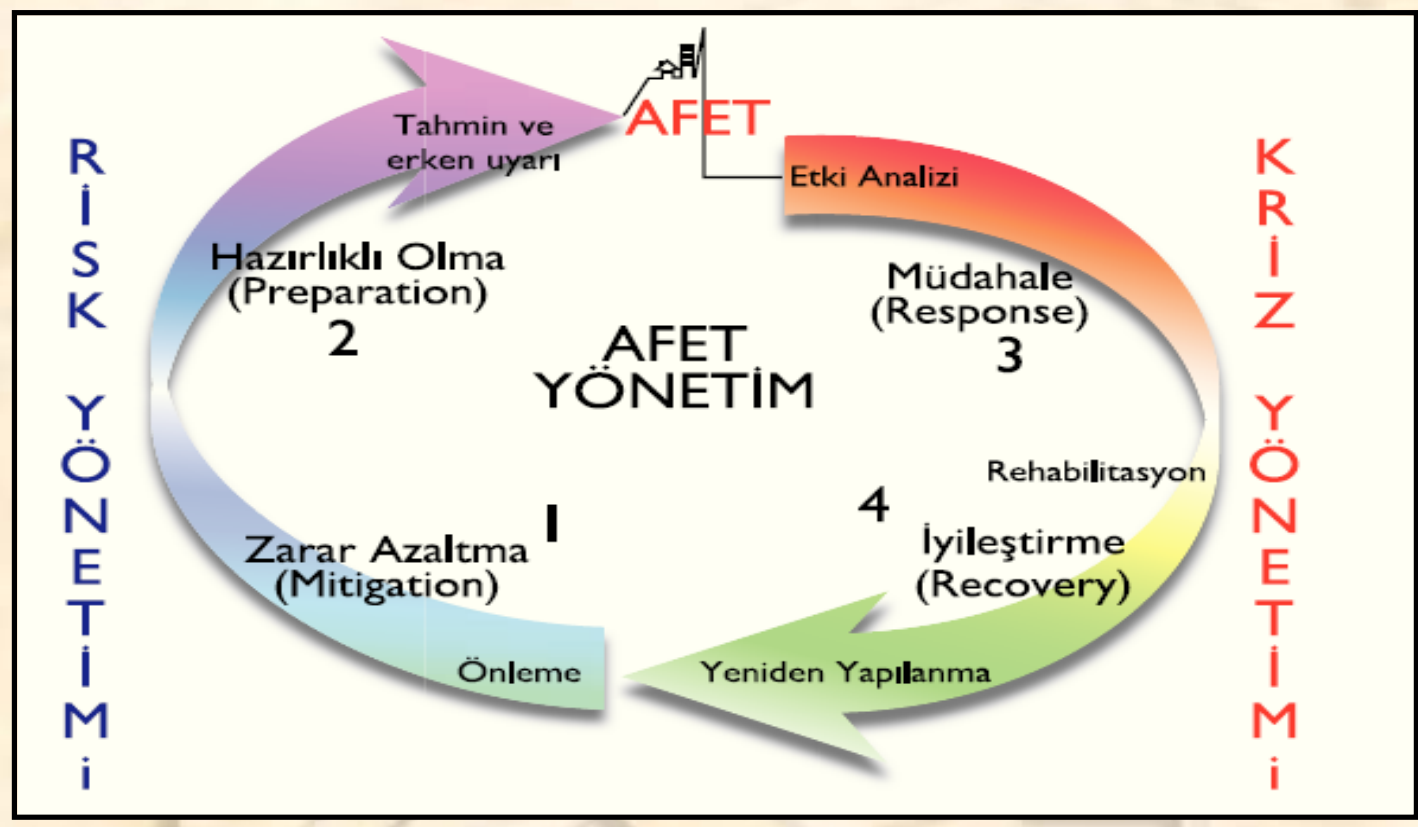

Şekil 1. Afet yönetim sisteminin aşamaları (Url-1)

Afet yönetimi her safhada yapılması gereken faaliyetlerin planlanması için toplumun tüm kuruluşlarıyla kaynaklarının ortak amaç doğrultusunda kullanılmasını gerektiren kapsamlı bir yönetimdir. Çeşitli bilgiye sahip olan insanların ve farklı kuruluşların bir arada çalışması ile etkin bir afet yönetimi ortaya çıkarılabilmesi mümkündür (FEMA, 2002).

Afet yönetiminin temel hedefleri, can ve mal kayıplarına neden olacak risklerin etkisini en düşük seviyeye indirmek, afetten birinci derecede zarar gören insanları kurtarmak, kültürel ve doğal çevre varlıklarını korumak, afet sonrasında toplumsal yaşamı en kısa sürede olağan döngüsüne kavuşturmak, sürdürülebilir kalkınmayı, hizmetlerin devamını ve üretimin sürekliliğini sağlamaktır (Alahi, 2018).

\section{Kentsel Hassasiyetler ve Risk Analizi}

Farklı kullanımların karmaşıklığı, doku yoğunluğu ve daha büyük nüfus nedeniyle şehirler, kırsal alanlara oranla daha hassastır (şekil 2). Kentsel hassasiyetin değerlendirilmesinde önerilen yöntem, mekânsal çok kriterli analiz tekniklerine dayanmaktadır. Mekânsal olarak yönlendirilen veriler birleştirilir ve sonuçta ortaya bir hassasiyet dokusu çıkartılır.

Hassasiyet, kentsel çevrenin, toplumsal ve fiziksel özelliklerine bağlı olarak, zarar görme olasılığı bulunan zayıf yönlerini tanımlarken, risk, kentsel alanlardaki hassas alanların tehlikelere maruz kalmaları halinde oluşacak potansiyel kayıpların derecesini ifade eder. Bir başka ifadeyle risk düzeyini tehlikenin büyüklüğü ve hassasiyet derecesi belirler (risk $=$ tehlike $\mathrm{x}$ hassasiyet) $($ Martins vd, 2012). Kentsel hassasiyet, Sosyo-Ekonomik, Kurumsal, Sistemsel, Ekolojik, Yöresel ve Yapısal-Fiziksel olmak üzere alt bileşenlerden oluşmaktadır.

Konunun daha anlaşılır olmasını sağlayacağı düşünesiyle, risk analizi olgusunu, dünyada en çok kayba yol açan jeofizik kökenli ve ani gelişen bir afet türü olan deprem üzerinden örneklemek daha açılayıcı olacaktır.

Deprem riskleri, belirli bir deprem senaryosunun varsayıldığ gibi veya olasılıksal olarak, depremin büyüklüğü, konumu ve meydana gelme zamanındaki belirsizliklerin açıkça göz önüne alındığı şekilde deterministik olarak analiz edilebilir. Bir başka ifadeyle deprem risk analizi, belirli bir alanda yer sarsıntısı tehlikelerinin kantitatif tahminini içerir. 


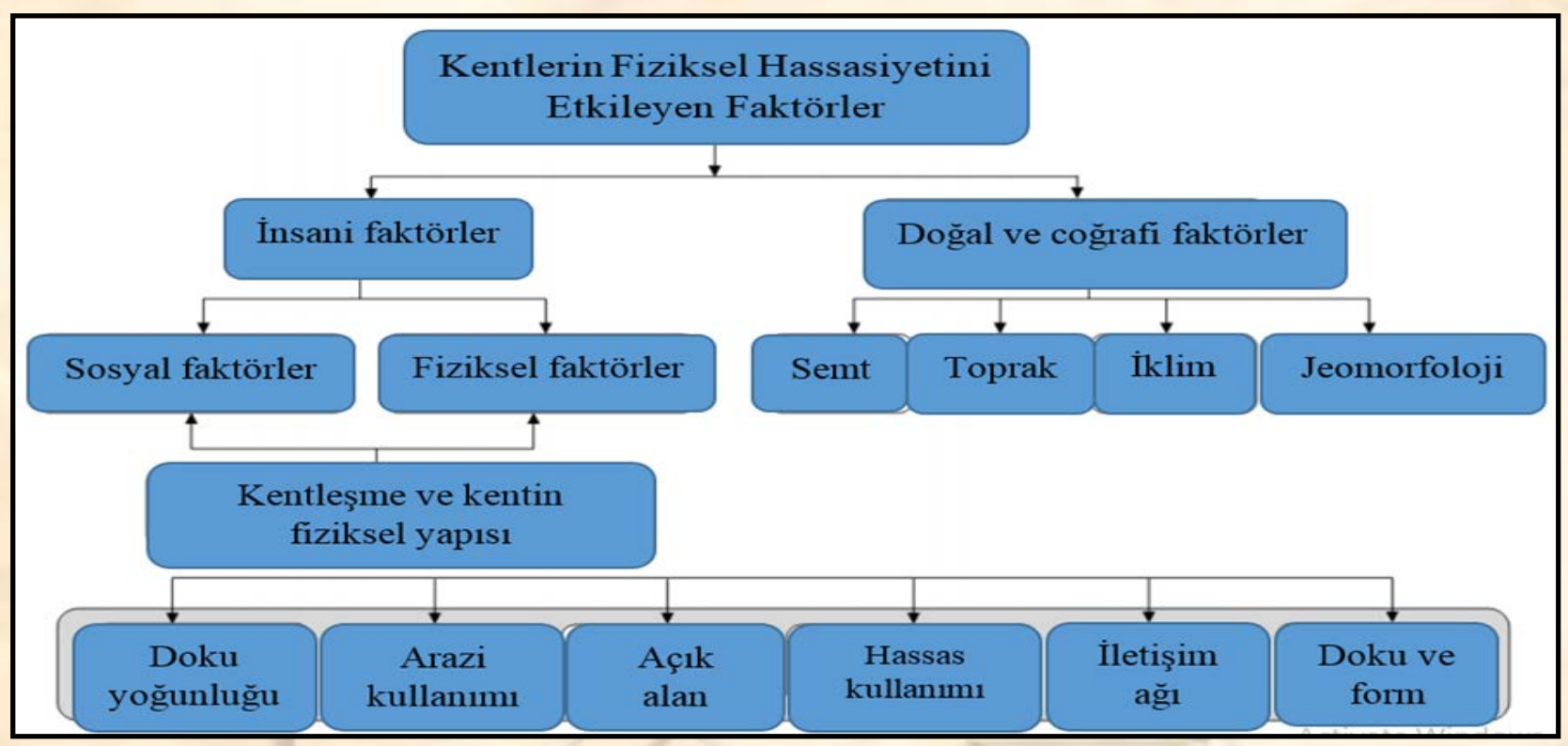

Şekil 2. Kentsel alanlarda fiziksel hassasiyeti etkileyen faktörler (OAS, 1991)

Deprem risk değerlendirmesi, tehlike tanımlaması, bu tehlikeyle ilişkili risklerin analiz edilmesi, tehlikeyi ortadan kaldırmak için uygun yolların belirlenmesi veya tehlikenin ortadan kaldırılamaması durumunda riskin kontrol edilmesi adımlarından oluşur (Opadeyi, 2010). Risk değerlendirmesi, genel süreci veya yöntemi tanımlamak için kullanılan bir terimdir ve farklı büyüklük ve yoğunluklarda belirli bir deprem setinin olasılığını ve potansiyel sonuçlarını tahmin etmek için gerekli çalışmaları kapsar (Samsunlu vd, 1999).

Genel olarak ifade etmek gerekirse, meydana gelme olasılığı, büyüklüğü, şiddeti, yeri gibi faktörlerin etkisi bağlamında bir tehlikenin fiziksel özellikleri belirlenir. Yapılı çevre, nüfus ve ekonomik aktivite gibi sosyoekonomik faktörler de dâhil olmak üzere risk altındaki unsurlar tanımlanarak hassasiyet analizi yapılır. Hassasiyet analizi ile risk altındaki öğelerin maruz kaldıkları tehlike karşısındaki duyarlılık dereceleri değerlendirilir. Farklı binalar ve inşaat türleri farklı hassasiyet eğrilerine sahip olmaktadır. Yukarıdaki bileşenlerin sentezleri ve sonuçta ortaya çıkan kayıpların geri dönüşünde bir fonksiyonu olarak veya bir aşma olasılığı olarak risk düzeyi belirlenmiş olur (Devrimi ve Vakifi, 1996).

\section{HAZUS (Hazard United States)}

HAZUS Federal Acil Durum Yönetimi Ajansı (FEMA)'nın kontrolünde deprem, tsunami, sel ve kasırgalara maruz kalan alanlardaki potansiyel bina ve altyapı kayıplarını tahmin eden ulusal olarak uygulanan bir yazılımdır. Sistem FEMA tarafından finanse edilmiş ve 1997 yılında Ulusal Yapı Bilimleri Enstitüsü (NIBS) tarafından geliştirilmiştir (FEMA, 2011).

Başlangıçta sadece deprem kayıp tahmini içeren sistem, diğer tehlikeleri de kapsayacak şekilde geliştirilmiş ve HAZUS-MH (Hazard United States-Mult Hazard) adını almıştır. HAZUS-MH kayıp tahminleri, en gelişmiş bilimsel ve mühendislik bilgisini yansıtmaktadır ve risk azaltma, acil durum hazırlığı, müdahale ve kurtarma planları ve politikalarının geliştirilmesi için bir temel sağlayarak tüm idari düzeylerdeki karar verme süreçlerinde kullanılabilir niteliktedir. HAZUS, deprem, sel, kasırgalar ve Tsunamiden kaynaklanan potansiyel kayıpları tahmin eden modelleri içeren, ulusal olarak uygulanabilir standart bir metodolojidir. HAZUS yazılımı, risk-bilinçli karar vermeyi desteklemek için afetlerin fiziksel, ekonomik ve popülasyon üzerindeki sosyal etkilerini tahmin ve analiz ederek haritalamak amacıyla Coğrafi Bilgi Sistemleri (CBS) teknolojisini kullanır (FEMA, 2000). HAZUS analizleri, bir felaket olayından sonra müdahale ve kurtarma eylemlerini desteklemek için gerçek zamanlı olarak da çalıştırılabilir (FEMA, 2011).

HAZUS Deprem Modeli ilk olarak 1997 yılında FEMA tarafından HAZUS97 olarak yayınlanmış ve daha sonra üç kez güncellenmiştir. Model sonuçları detaylı mühendislik verileri ve varsayımlarına dayanmasına rağmen HAZUS, 
bir mühendislik aracı değil, planlama ve etki değerlendirme aracıdır. Bu metodolojinin en son versiyonu, deprem, sel kasırga ve tsunami gibi tehlikeleri de içeren HAZUS MH MR-4.2 Service Pack 3 adıyla 31 Mayıs 2019'da kullanıma alınmıştır. Tehlike verileri haritalanarak, binalar ve altyapılar için olası risk tahminleri CBS ortamında elde edilir. Model, bu unsurların envanterine dayalı olarak nüfus, bina, ulaşım sistemi, cankurtaran araçları ve tehlikeli maddeler gibi çeşitli bileşenlerin sınıflandırılması üzerinde çalışmaktadır (Url-2). Sistem, hazırlık ve müdahale ile birlikte, azaltma ve geri kazanma için de kullanılır. Hükümet yetkilileri, plancılar, CBS uzmanları ve acil durum yöneticileri zararları ve bunları en aza indirmek için alınacak en faydalı yaklaşımları belirlemek için HAZUS'tan faydalanır. Bir toplumun afet kayıplarını azaltmak ve afet hasarı, yeniden yapılanma ve tekrarlanan hasar döngüsünü kırmak için uzun vadeli stratejinin temeli olan risk azaltma planlama sürecindeki değerlendirme aşamasında HAZUS vazgeçilmez bir araçtır (FEMA, 1996).

Geniş bir kesime açık olan sistemin başlıca kullanıcıları kent plancıları, risk azaltma planlaması uzmanları, konuyla ilgili merkezi ve yerel kamu kurumlarındaki CBS personeli, bölgesel planlama komisyonları, üniversiteler, araştırmacılar, öğrenciler ve danışmanlar olup bunlarla sınırlı değildir (FEMA, 2011).

İş akışı risk değerlendirme sürecindeki adımlara göre düzenlenir (şekil 3). Her adımda HAZUS çıktılarının nasıl kullanılabileceği ve bir risk değerlendirmesine dâhil edilebileceği tartışılmaktadır. Bu metodolojinin en önemli bileşenlerinden biri, risk değerlendirmesi için gerekli olan risk ve tehlike unsurlarının tutulduğu kapsamlı bir veri tabanıdır. HAZUS sistemi genel yapı stokunun bir envanteri, belirli özelliklere sahip bina gruplarının toplam alandaki dağılımı ve nüfus büyüklüğü üzerinde çalışmak üzere kurgulanmıştır. Bu nedenle metodoloji, en küçük coğrafi birim olan yollara dayanmaktadır. Alandaki modüller, 2500 ila 8000 nüfusu içerecek şekilde tasarlanmıs arazi parçalarıdır. Sistem, ülke içindeki tüm alanı tamamen ve benzersiz bir şekilde tanımlayabilmektedir (FEMA, 2011).

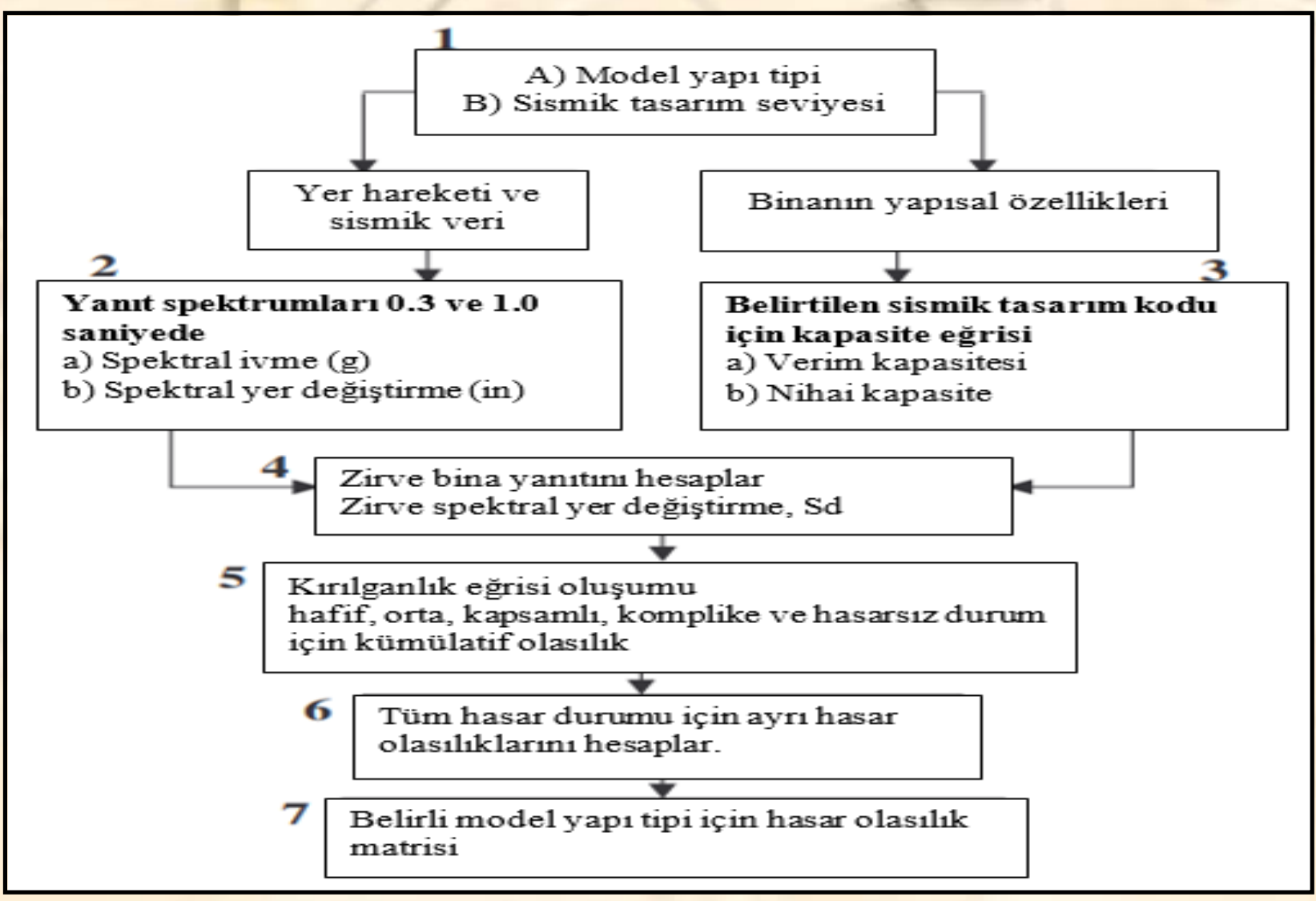

Şekil 3. HAZUS metodolojisi akış şeması (FEMA, 2000) 


\subsection{HAZUS sisteminde girdiler ve çıktılar}

HAZUS' a üç tür veri girişi dâhil edilmiştir. Bunlar, varsayılan veriler, bölge özellikleri ve özel tehlikelerdir (şekil 4) (FEMA, 2011).

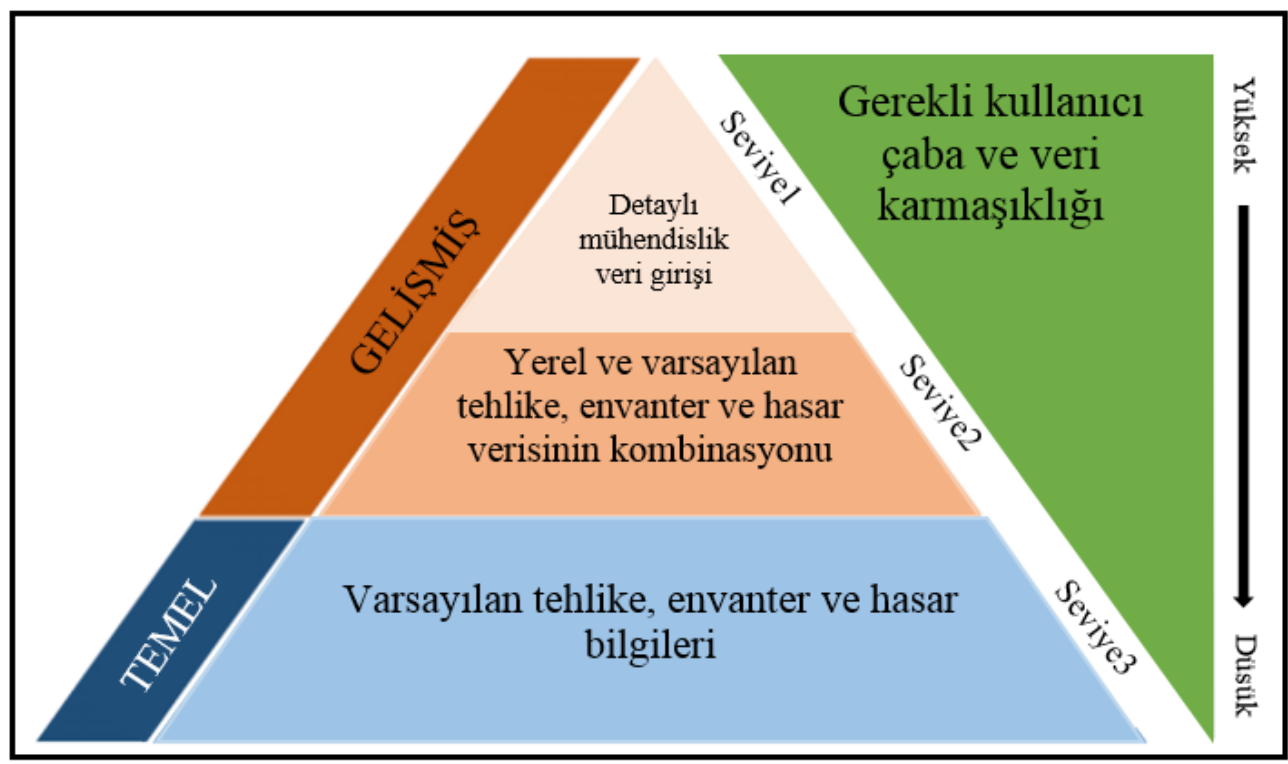

Şekil 4. HAZUS analiz seviyesi (FEMA. 1999)

Varsayılan veriler, tüm tehlike modelleri arasında ortak olan bir bilgi koleksiyonunu temsil eder. HAZUS'a sağlanan envanter veri setinde yedi kategori vardır (FEMA, 2011). Bunlar, genel bina stoku, temel tesisler, yüksek potansiyel kayıp tesisleri, tehlikeli madde tesisleri, ulaşım sistemleri, yaşamsal altyapı sistemleri, demografik özelliklerdir. Kullanıcı, bir HAZUS analizinin çıktısının kapsamını ve niteliğini seçme konusunda önemli bir rol oynamaktadır. Zararın kapsamını görselleştirmek için çeşitli haritalar oluşturulabilir. Sayısal sonuçlar, sayım bloğu ya da kanal düzeyinde incelenebilir, ilçe ya da bölge tarafından toplanabilir (FEMA, 2000). HAZUS-MH sisteminde farklı tehlike türlerine göre analizlere veri sağlayan girdi türleri ve sonuçta elde edilen çıktılar çizelge 1'de gösterilmektedir. 
Çizelge 1. HAZUS çıkışlar (FEMA 2011).

\begin{tabular}{|c|c|c|c|c|}
\hline $\begin{array}{l}\text { HAZUS'un } \\
\text { yetenekleri }\end{array}$ & $\begin{array}{c}\text { Deprem } \\
\text { Yer Sarsıntısı } \\
\text { Zemin Kusuru }\end{array}$ & $\begin{array}{c}\text { Sel } \\
\text { Frekans / Akarsu Derinliği / } \\
\text { Kıyı Dalgalanması }\end{array}$ & $\begin{array}{c}\text { Kasırga } \\
\text { Rüzgar / Dalgalanma }\end{array}$ & $\begin{array}{c}\text { Tsunami } \\
\text { Derinlik / Momentum Akışı } \\
\text { / Dalga Yüksekliği / Hız }\end{array}$ \\
\hline \multicolumn{5}{|c|}{ Girdiler } \\
\hline Tarihsel & $\sqrt{ }$ & & $\sqrt{ }$ & \\
\hline Deterministik & $\sqrt{ }$ & $\sqrt{ }$ & $\sqrt{ }$ & $\sqrt{ }$ \\
\hline Olasılıksal & $\sqrt{ }$ & $\sqrt{ }$ & $\sqrt{ }$ & \\
\hline $\begin{array}{c}\text { Kullanıcı Tarafından } \\
\text { Sağlanan }\end{array}$ & $\sqrt{ }$ & $\sqrt{ }$ & $\sqrt{ }$ & $\sqrt{ }$ \\
\hline Diğer Ek Girdiler & $\begin{array}{c}\text { Gerçek Zamanlı \& } \\
\text { USGS Senaryo Sarsıntı } \\
\text { Haritaları }\end{array}$ & $\begin{array}{c}\text { Risk Haritası, Kullanıcı } \\
\text { Tarafından Sağlanan Derinlik } \\
\text { Örüntüsü (ArcGRID, } \\
\text { GeoTIFF, IMAGINE), HEC- } \\
\text { RAS(.FLT) }\end{array}$ & $\begin{array}{c}\text { HURREVAC (ABD } \\
\text { Kasırga Programı Karar } \\
\text { Destek Yazılımı), } \\
\text { Kullanıcı Tarafindan } \\
\text { Sağlanan Rüzgar Dosyaları } \\
\text { (.dat) }\end{array}$ & $\begin{array}{l}\text { NOAA PMEL SIFT (ABD } \\
\text { Tsunami Araştırmaları } \\
\text { Merkezi Veri Tabanı), } \\
\text { Durum Modelleri }\end{array}$ \\
\hline \multicolumn{5}{|c|}{ Doğrudan Hasar } \\
\hline Genel Yapı Stoku & $\sqrt{ }$ & $\sqrt{ }$ & $\sqrt{ }$ & $\sqrt{ }$ \\
\hline Temel Tesisler & $\sqrt{ }$ & $\sqrt{ }$ & $\sqrt{ }$ & \\
\hline Taşıma Sistemleri & $\sqrt{ }$ & $\sqrt{ }$ & & \\
\hline Yardımcı Sistemler & $\sqrt{ }$ & $\sqrt{ }$ & & \\
\hline $\begin{array}{c}\text { Kullanıcı } \\
\text { TanımlıTesisler }\end{array}$ & $\sqrt{ }$ & $\sqrt{ }$ & $\sqrt{ }$ & $\sqrt{ }$ \\
\hline \multicolumn{5}{|c|}{ Zincirleme Hasarlar } \\
\hline Yangın & $\sqrt{ }$ & & & \\
\hline Enkaz Oluşumu & $\sqrt{ }$ & $\sqrt{ }$ & $\sqrt{ }$ & \\
\hline \multicolumn{5}{|c|}{ Doğrudan Kayıplar } \\
\hline Onarım Maliyeti & $\sqrt{ }$ & $\sqrt{ }$ & $\sqrt{ }$ & $\sqrt{ }$ \\
\hline Gelir Kayb1 & $\sqrt{ }$ & $\sqrt{ }$ & $\sqrt{ }$ & $\sqrt{ }$ \\
\hline Tarımsal & & $\sqrt{ }$ & & \\
\hline $\begin{array}{l}\text { Can Kaybı / } \\
\text { Yaralanma }\end{array}$ & $\sqrt{ }$ & & & $\sqrt{ }$ \\
\hline $\begin{array}{c}\text { Barınma ve/veya } \\
\text { Tahliye Gereksinimi }\end{array}$ & $\sqrt{ }$ & $\sqrt{ }$ & $\sqrt{ }$ & $\sqrt{ }$ \\
\hline Yıllık Ortalama Kayıp & $\sqrt{ }$ & $\sqrt{ }$ & $\sqrt{ }$ & \\
\hline
\end{tabular}

\section{AYDES (Afet Yönetimi ve Karar Destek Sistemi)}

Türkiye Afet Müdahale Planı (TAMP) altyapısında olan AYDES, AFAD (Afet ve Acil Durum Yönetimi Başkanlığı) tarafından TÜRKSAT işbirliği ile geliştirilmiştir. Ulusal afet ve acil durumların etkin bir biçimde yönetilmesini sağlayan CBS (coğrafi bilgi sistemi) destekli web tabanlı bir platformdur (URL-3).

Sistem, Afet ve Acil Durum (Kriz) Yönetimine ilişkin;

- afet öncesi (hazırlık ve zarar azaltma),

- afet sirası (müdahale),

- afet sonrası (iyileştirme), 
süreçlerinin Afet ve Acil Durum Yönetimi Başkanlığı tarafından kontrol ve koordine edilmesine yönelik olarak kurgulanmıştır (Şekil 5).
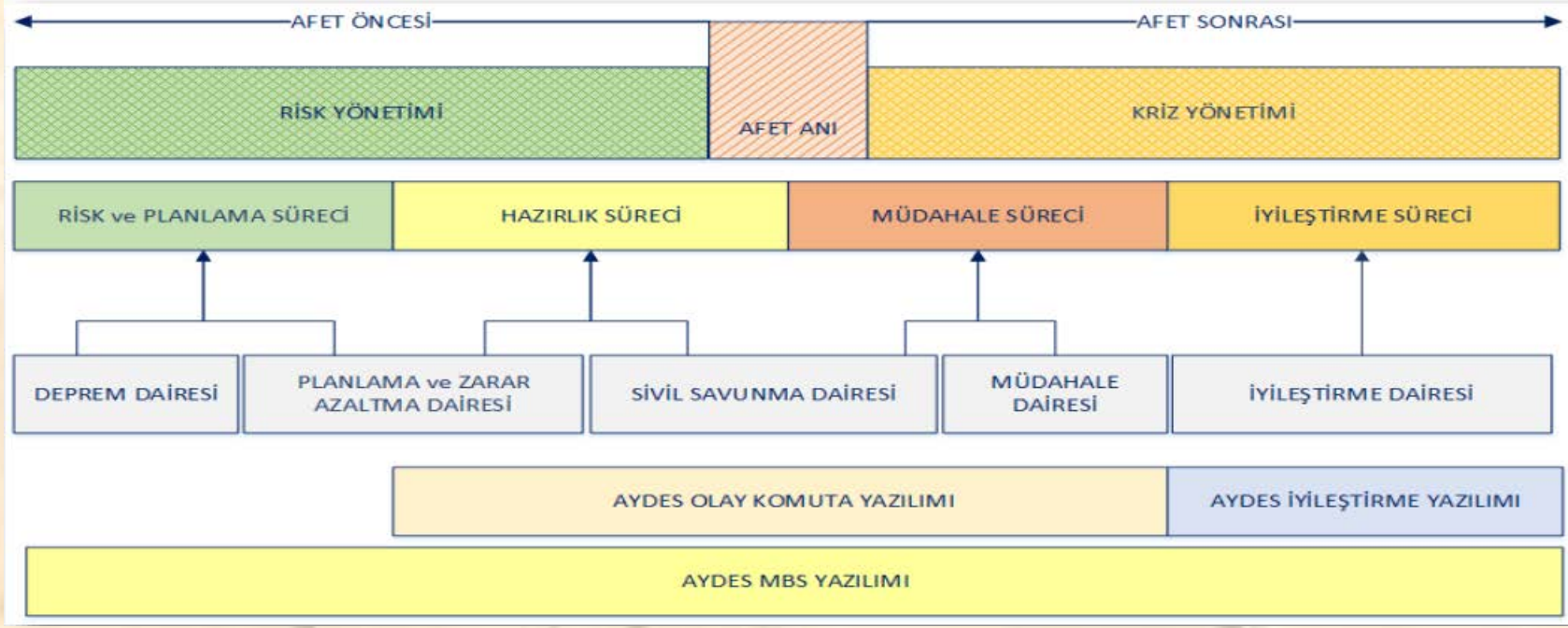

Şekil 5. AYDES kapsamında afet yönetim süreci (URL-4)

AYDES sistemi, Türkiye Afet Müdahale Planı (TAMP) kapsamında ihtiyaç duyulan bilişim altyapısı ve karar destek sistemi merkezli yönetim modelinin kurulması ve etkin yürütülmesi, bu çerçevede sürdürülebilir afet yönetimi ve bilgi sistemi oluşturulmasını amaçlamaktadır. Sistem, Türkiye'de Afet ve Acil Durum Yönetimi Başkanlığı (AFAD), ilgili Bakanlıklar ve taşra teşkilatları tarafından kullanılmaktadır. Olay Komuta Sistemi, Mekânsal Bilgi Sistemi ve İyileştirme Sistemi olarak üç ana bileşene ayrılmıştır ve bunlara ait alt bileşenlerden oluşmaktadır (şekil 6).

Olay Komuta Sistemi, Türkiye Afet Müdahale Planı (TAMP) kapsamındaki çalışma gruplarının planlama, hazırlık ve müdahale süreçlerinin bütünleşik bir sistem üzerinde yönetimini sağlar. Acil durumlarda oluşan ihtiyaçlar kaynak, talep ve nakliye yönetimi süreçleri ile etkin ve esnek şekilde yönetilebilir. Afet gerçekleştiği andan itibaren olay bildirimleri e-posta ve SMS ile ekiplere gönderilir ve ekipler e-posta ve mesajlaşma yoluyla sistem üzerinde iletişim halinde kalabilmektedir. Olay Komuta Sistemi afet ve acil durum olayına neden olan ve etkileyen tüm parametrelerin izlenmesini, değerlendirilmesini, analiz edilmesini ve birimlerin koordinasyonunu sağlamaktadır (URL-4). Olay Komuta Sisteminin bileşenleri, il bazında yapılmış olan afet müdahale planları, çalışma grupları bilgi formları, kaynak yönetimi, organizasyonel yapı, olay yönetim sistemi, müdahale sistemi, gösterge paneli, dahili mesajlaşma sistemi, kritik tesis verilerinden oluşur.

Mekansal Bilgi Sistemi CBS kullanarak sürdürülebilir bir afet yönetim sistemi oluşturulmasını sağlamaktadır. Sistem, afet öncesi, sırası ve sonrasında bilgiye hızlı bir şekilde ulaşabilecek ve afetten etkilenen alanlar ile olası bir afetin etkileyeceği bölgelerde yapılacak mekânsal planlamada hızlı karar üretebilecek şekilde tasarlanmıştır. Sistem alt bileşenleri ve menüleri farklı haritalar sunarak mekânsal bilgilerin gerçek zamanlı olarak sorgulanabilmesine, güncellenebilmesine, düzenlenebilmesine, sonuçların ve raporların çıktı olarak alınabilmesine imkân sağlamaktadır (URL-4).

İyileştirme Sistemi, Mekânsal Bilgi Sistemi ve CBS desteği ile afet sonrasında yapılması gereken çalışmaların bilişim ortamında gerçekleştirilebilmesi için tasarlanmıştır. Ayrıca sistemin hasar tespit mobil uygulamalarıyla desteklenmesi, özellikle sahada yapılan çalışmalardan konum içerikli bilgi toplanmasını ve bunların merkezi sistemde kaydedilmesini sağlamaktadır. İyileştirme Sistemi, acil yardım, hasar tespit, jeolojik etüt raporları, hak sahipliği, yer seçimi, imarplan-proje, yatırım programı ve mobil uygulamalar gibi bileşenleri içermektedir (URL-3). 


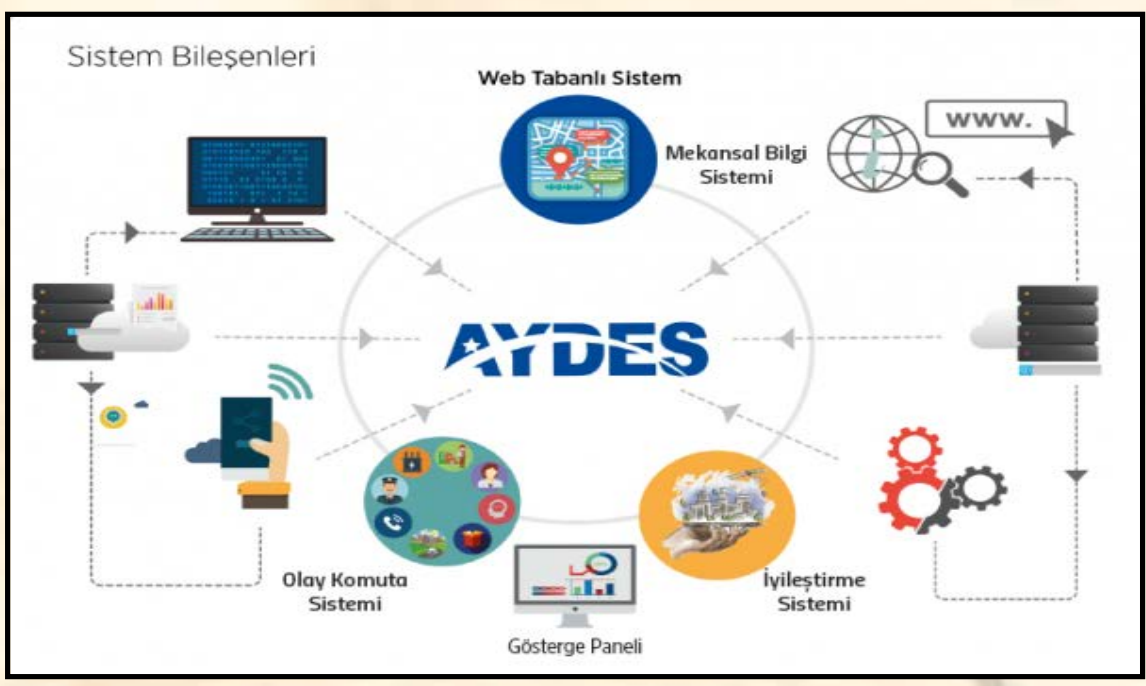

Şekil 6. AYDES sistemi bileşenleri (URL-3)

Tek bir merkezden (AFAD) temin edilen ve ulusal düzeyde tüm kullanıcıların afet yönetimi ihtiyacını karşılayacak şekilde tasarlanan AYDES 'in, mevcut yerel ve kurumsal afet yönetim sistemlerini ikame etmesi ve büyük bir maliyet tasarrufu sağlanması hedeflenmektedir (URL-3).

Afet öncesi ve sonrasında yapılması gereken çalışmalar ve önlemlerle kayıplar en aza indirilebilir. Bu bağlamda AYDES, sadece afetlerin konumlarının belirlenmesi, gözlemlenmesi ve etkilerinin tespit edilmesi değil, bunlara ilave olarak afet öncesinde ve sonrasında her düzeydeki kullanıcısına afet ve acil durumlar konusunda karar desteği sunan pek çok seçeneği de kapsamaktadır.

AYDES mimarisi verilerin farklı kaynaklardan toplanmasına ve bu verilerin CBS tabanlı veriler ile eşleştirilerek gerekli veri tabanları ile bağlantı kurulmasına imkân sağlamaktadır (şekil 7). Elde edilen veriler yöneticilere sunulabilmekte ayrıca karar destek ve rapor altlıklarına dönüştürülebilmektedir (URL-4).

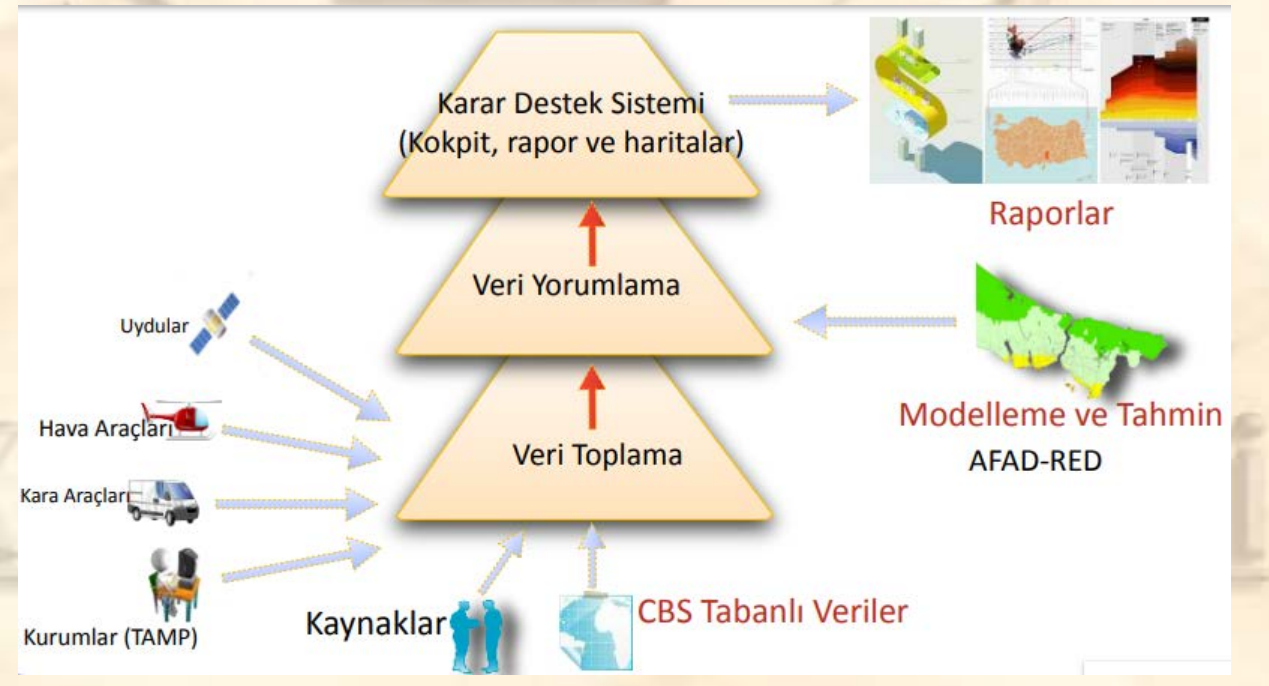

Şekil 7. AYDES genel mimarisi (URL-4)

AYDES bu özellikleri ile afet zararlarının en aza indirilmesi, afete maruz kalan insanların kurtarılması, yaralıların tahliyesi, acil durumların kontrolü açısından önemli bir sosyal yarar sunmaktadır (URL-3). 


\section{TARTIŞMA VE SONUÇ}

Araştırmalar, dünyada birçok büyük kentin afete yol açabilecek tehlikeler altında olduğunu, öte yandan bu kentlerdeki aşırı nüfus yoğunluğunun riskleri arttırdığını, fakat risk belirlemenin zorlukları nedeniyle kentlerde belirsiz bir gelecek oluştuğunu göstermektedir. Uygun bir afet yönetim sisteminin eksikliği durumunda doğal afetlerin büyük kayıplara yol açan felaketlere dönüştüğü sonuçlar yaşanacaktır. Son yıllarda yangınlar, şiddetli firtınalar, büyük depremler ve su baskınları gibi dünyanın birçok ülkesinde meydana gelen olaylar, özellikle kentlerde afet yönetiminin gerekliliğine işaret etmektedir.

Kent planlama, kentin afet direncinin artmasında en önemli role sahiptir. Arazi kullanımında yer seçimi, nüfus yoğunluğunun dengeli dağılımı, erişilebilirlik, kentsel teknik altyapının niteliği ve kapasitesi, dezavantajlı grupların yaşam kalitesinin yükseltilmesi, gerekli alanlarda yapı stokunun yenilenmesi, sosyal altyapının afet anındaki müdahale kapasitesini arttıracak şekilde konumlandırılması ve donatılması gibi kararlar kent planlama disiplininin çözüme kavuşturacağı sorunlardır.

Kent planlamanın risklerin azaltılması hedefine yönelik vereceği kararların sağlıklı olabilmesi ise bu sorun alanlarındaki verilerin üretilmesinden sorumlu olan diğer disiplinlerle ortak bir platformda çalışma olanağının varlığı ile mümkün kılınabilir. Bütünleşik afet yönetiminin önemi ise burada anlaşlır olmaktadır. Zira gerek risk azaltma çalışmalarını bünyesinde toplayan risk azaltma planlamasının gerçekleştirildiği risk yönetimi safhası, gerekse afet sonrası çalışmaların koordine edildiği kriz yönetimi safhası birbirleri ve kent planları ile bütünleşik olmadıkları müddetçe hedefe ulaşamayacaktır.

Bu çerçevede, HAZUS sisteminin afet yönetimi sürecinde efektif bir araç olduğu görülmektedir. Gerek veri girişi yetkisinin gerekse bu verileri sentezleyerek bilgi üretme yetkisinin farklı kurumlara, uzmanlıklara ve sorumlulara tanımlanmış olması yetkin ve yaygın bir afet yönetim sürecinin örgütlenebilmiş olduğunun da bir göstergesidir. AYDES'in bu noktadaki zayıf yönü ise sisteme veri girme ve çıtı üretme yetkisinin oldukça kısıtlı tutulmuş olmasıdır. Bu durum sistemin yetkilendirilmiş kamu kurumlarındaki ekipler dışında kalan meslek uzmanları, akademisyenler, bilim çevreleri, yerel yönetim bileşenleri ve afet yönetiminde rol üstlenen sivil toplum kuruluşları tarafından tecrübe edilememesine ve geliştirilmesine yönelik katkılardan mahrum kalmasına yol açmaktadır. Bu noktada, yaygın kullanımı, geniş kullanıcı kitlesinden gelen geri beslemelere ve afet sonrası performansa bağlı olarak sürekli güncellenmesi HAZUS'un en önemli avantajı olarak öne çıkmaktadır.

Bütünleşik Afet Yönetim Sisteminde prensip, tüm afetlere duyarlı bir sistemin teşekkül etmesi ve yetki ve sorumlulukların yerel yönetimleri de kapsayacak şekilde geniş bir tabana yayılarak şeffaf bir yapıya kavuşturulmasıdır. Ülkemizin büyük bir bölümünün çoklu afet tehlikesi altında olduğu gerçeğinden hareketle, AYDES sisteminin afet risklerini bertaraf etme ve afet sonrası olağan yaşam koşullarına en kısa sürede geri dönme sürecinde çok büyük yarar sağlayacak önemli bir araç olduğu göz ardı edilmemeli ve bu doğrultuda sistemin geliştirilmesi için çaba sarf etmekten ve yapıcı öneriler sunmaktan geri durulmamalıdır. 
Başta İstanbul olmak üzere, ülkemizde özellikle deprem tehlikesi yüksek bölgelerde üretilmiş olan çok geniş ve değerli veri tabanlarının yerel afet yönetim süreçlerinde etkin kullanılabilmesi hem AYDES'in kapasitesini ve etkinliğini artıracak hem de ülkemiz kaynaklarının daha verimli kullanılmasına olanak sağlayacaktır. Bu anlamda kentlerimizin afet direncinin arttırılması, olası kayıpların asgariye indirilmesi ve hem toplumsal hem de ekonomik negatif etkilerin azaltılması ile sürdürülebilir kalkınma yolunda önemli bir eşik aşılmış olacaktır.

\section{KAYNAKLAR}

1. Alahi, F.N., (2018). Tahran Deprem Afeti Yönetim Programına Yaklaşımla Büyük Şehirler Depreminin Yönetimi, Tehran, İran: Uluslararası Sismoloji Enstitüsü ve Deprem Mühendisliği.

2. Demirci, A., ve Karakuyu, M., (2004). Afet Yönetiminde Coğrafi Bilgi Teknolojilerinin Rolü, Doğu Coğrafya Dergisi.

3. Devrimi, İ., Vakfı, K., (1996). Deprem riskini azaltmak için alanların mekansal ve uzaysal analizi ve planlanması , Miyan şehir, İran

4. Filemon, A., Uriarte, Jr., (2008). Introduction to knowledge management, A brief introduction to the basic elements of knowledge management for non-practitioners interested in understanding the subject, National academy of Science and Technology, Asean Foundation, Jakarta, Indonesia.

5. FEMA, (2000). Recommended Seismic Evaluation and Upgrade Criteria for Existing Welded Steel MomentFrame Buildings, Washington, D.C., FEMA, 351.

6. FEMA, (2011). EARTHQUAKE LOSS ESTIMATION METHODOLOGY HAZUS MH 2.1, Advanced Engineering Building Module (AEBM), Department of Homeland Security Federal Emergency Management Agency Mitigation Division Washington, D.C.

7. FEMA, (2002). Federal Response Plan, 9230.1-P Supersedes FEMA 229, April 1992.

8. FEMA-287, (1996). HAZUS: The FEMA Tool for Estimating Earthquake Losses, Federal Emergency Management Agency, Washington, D.C.

9. FEMA, (1999). HAZUS99, Technical Manual, Federal Emergency Management Agency, Washington, D.C.

10. Gispen, W. H., (2002). Urban Disaster Management, A Case Study of Earthquake Risk Assessment in Cartago, Costa Rica: Utrecht University and ITC.

11. İbrahimi, M., Cezayirli, SA., (1995). “Iran İslam Cumhuriyeti Afet Yönetim Planı", 2. Uluslararası Deprem ve Deprem Konferansi Bildirileri, Tehran, İran.

12. Khorram. Manesh, A. (2017). Handbook of disaster and emergency management, Sweden: Gothenburg.

13. Martins, V. N., Silva, D. S., Cabral, P., (2012). Social vulnerability assessment to seismic risk using multi criteria analysis: the case study of Vila, Franca.

14. Opadeyi , J., (2010). Perspectives on Earthquake Risk Assessment and Management in Trinidad and Tobago, Department of Geomatics Engineering and Land Management, The University of the West Indies, St. Augustine, Trinidad, West Indies.

15. OAS, (1991). Primer on Natural Hazard Management in Integrated Regional Development Planning. Organization of American States, Washington, DC.

16. Özmen, B., Nurlu, M., Kuterdem, K., Temiz, A., (2005). Afet Yönetimi ve Afet İsleri Genel Müdürlüğü. Deprem Sempozyumu 2005, 23-25 Mart 2005, Grand Yükseliş Hotel, İzmit.

17. Rezayiyan, A., (2002). Afet yönetimi, ilk bilimsel araştırma konferansının bildirileri, Uygulamalı Yüksek Öğretim Enstitüsü, Tehran İran. 
18. Samsunlu, A., Tanık A., Eroğlu, V., (1999). Urban Impacts and Probable Effects of Earthquakes on The Infrastructure of a Megacity, Istanbul, Proceedings of ITU - IAHS International Conference on The Kocaeli Earthquake, December 2-5, İstanbul.

19. URL-1,https://docplayer.biz.tr/10049587-Afet-ve-acil-mudahale-bilgi-sistemi-yard-doc-dr-mehmet-fatihdoker.html (23.05.2019)

20. URL-2, https://www.fema.gov/hazus-modernization (11.08.2019)

21. URL-3,https://www.afad.gov.tr/tr/3639/Afet-Yonetim-ve-Karar-Destek-Sistemi-Projesi-AYDES (05.10.2019)

22. URL-4 https://docplayer.biz.tr/644243-T-c-basbakanlik-afet-ve-acil-durum-yonetimi-baskanligi-ay-d-e-safet-yonetim-ve-karar-destek-sistemi-genel-tanitim.html (pdf, 11.12.2019) 